\title{
PERANCANGAN TUNGKU PEMANAS DENGAN MENGGUNAKAN KANTHAL A1
}

\author{
Dwi Purwanto \\ Fakultas Teknik dan Sains, Program Studi Teknik Mesin \\ Universitas Muhammadiyah Purwokerto \\ Email: dwipurwanto@ump.ac.id \\ Reza Azizul Nasa \\ Fakultas Teknik dan Sains, Program Studi Teknik Mesin \\ Universitas Muhammadiyah Purwokerto \\ Email: Reza@ump.ac.id
}

\begin{abstract}
ABSTRAK
Beberapa material logam banyak dipakai atau digunakan sebagai bahan konstruksi bangunan dan sebagai perkakas untuk mesin industri. Perlakuan panas merupakan satu rangkaian siklus panas meliputi pemanasan, penahanan temperatur, dan pendinginan. Biasanya dilakukan terutama pada logam atau paduan dalam kondisi padatan. Perlakuan panas pada logam dapat dilakukan dengan berbagai macam cara, dan salah satunya yaitu perlakuan panas dengan pemasan menggunakan tungku. Metode perancangan tungku ialah menggunakan elemen kawat kanthal A1 yang dipanaskan menggunakan energi listrik untuk menghasilkan panas pada filamen yang terdapat pada dinding tungku, sampai temperatur maksimal $1200^{\circ} \mathrm{C}$ sehingga diharapkan dapat meningkatkan sifat mekanis pada bagian permukaan baja tersebut. Hasil rancangan pada penelitian ini akan dilakukan pada laboratorium teknik mesin di universitas muhammadiyah purwokerto. Material utama yang digunakan adalah material refraktori dengan menggunakan daya listrik sebesar 8205,1 watt dengan konsumsi pemakain listrik $4.9 \mathrm{kWh}$ dengan temperature maksimum $1200^{\circ} \mathrm{C}$.
\end{abstract}

Kata kunci: kanthal A1, tungku, perancangan, refraktori,

\begin{abstract}
Most of the building construction materials and industrial machine tools using steel for industrial machinery. Heat treatment is a series of heat cycles including heating, temperature holding, and cooling. Usually performed mainly on metals or alloys in solid state. Metal heat treatment can be done in various ways, and one of them is heat treatment by heating using a furnace. The furnace design method is to use Al kanthal wire elements which are heated using electrical energy to produce heat in the filaments contained in the furnace walls, up to a maximum temperature of $1200^{\circ} \mathrm{C}$ so that it is expected to improve the mechanical properties of the steel surface. The results of the design in this study will be carried out in the mechanical engineering laboratory at Muhammadiyah University of Purwokerto. The main material used is refractory material using an electric power of 8205.1 watts with an electricity consumption of $4.9 \mathrm{kWh}$ with a maximum temperature of $1200^{\circ} \mathrm{C}$.
\end{abstract}

Keywords: kanthal A1, furnace, design, refractory 


\section{PENDAHULUAN}

Pengecoran adalah suatu proses manufaktur yang menggunakan logam cair dan cetakan untuk menghasilkan parts atau komponen dengan bentuk yang mendekati bentuk geometri akhir produk jadi. Logam cair akan dituangkan atau ditekan ke dalam cetakan yang memiliki rongga sesuai dengan bentuk yang diinginkan. Setelah logam cair memenuhi rongga dan kembali ke bentuk padat, selanjutnya cetakan disingkirkan dan hasil cor dapat digunakan untuk proses sekunder.

Pemanas listrik adalah salah satu peralatan yang banyak digunakan dikehidupan sehari-hari, prinsip kerjanya adalah dengan menggunakan suatu elemen pemanas yang dialiri oleh arus listrik. Kemudian, energi listrik dirubah menjadi energi panas yang terjadi pada elemen pemanas. Panas yang timbul disebabkan karena material elemen pemanas terbuat dari logam yang memiliki resistansi yang tinggi. [1].

Untuk memanaskan logam dibutuhkan suatu alat yang disebut dengan tungku, tungku dilihat dari segi energi panas yang ditransfernya terbagi kedalam dua kelompok, yaitu tungku yang memanfaatkan energi panas yang dihasilkan oleh proses pembakaran gas, dan tungku yang menghasilkan panas yang memanfaatkan listrik sebagai sumber energinya (tungku induksi). Definisi tungku induksi yaitu tungku listrik yang memanfaatkan prinsip induksi untuk memanaskan logam hingga titik leburnya dimana panas yang diterapkan oleh pemanasan induksi medium konduktif (biasanya logam). Frekuensi operasi berkisar dari frekuensi yang digunakan antara $60 \mathrm{~Hz}$ sampai dengan $400 \mathrm{kHz}$ bahkan bisa lebih tinggi hal tersebut tergantung dari material yang mencair, kapasitas tungku dan kecepatan pencairan yang diperlukan. Medan magnet ini juga akan melakukan mixing pada logam cair akibat adanya gaya magnet antara koil dan logam cair yang akan menimbulkan efek pengadukan (stiring effect) untuk menghomogenkan komposisi pada logam cair [2].

Tungku adalah sebuah peralatan yang digunakan untuk mencairkan logam pada proses pengecoran (casting) atau untuk memanaskan bahan dalam proses perlakuan panas (heat Treatmet). Karena gas buang dari bahan bakar berkontak langsung dengan bahan baku, maka jenis bahan bakar yang dipilih menjadi penting. Sebagai contoh, beberapa bahan tidak akan mentolelir sulfur dalam bahan bakar. Bahan bakar padat akan menghasilkan bahan partikulat yang akan mengganggu bahan baku yang ditempatkan didalam tungku [2].

Khantal adalah jenis kawat pemanas yang cukup banyak digunakan sebagai elemen pemanas. Kawat khantal memiliki resistansi yang sangat tinggi yang merupakan paduan dari besi, kromium dan alumunium ( $\mathrm{FeCrAl})$ dapat beroprasi pada temperatur $1400 \mathrm{C}$ (2550 F). Kawat khantal biasanya digunakan untuk skala industri karena dapat bekarja pada temperatur dan tingkat, vketahanan oksidasi yang tinggi. Namun, memerlukan waktu yang lebih lama untuk mencapai temperatur yang diinginkan [3].

\section{METODOLOGI}

Prinsip kerja Tungku pemanas listrik adalah memanfaatkan prinsip induksi untuk memanaskan logam hingga titik leburnya dimana panas yang diterapkan oleh pemanasan induksi medium konduktif (biasanya logam) dan tidak menutup kemungkinan untuk material logam selain baja, diharapkan untuk merancang tungku pemanas dari listrik bisa sampai temperature $1200^{\circ} \mathrm{C}$. 


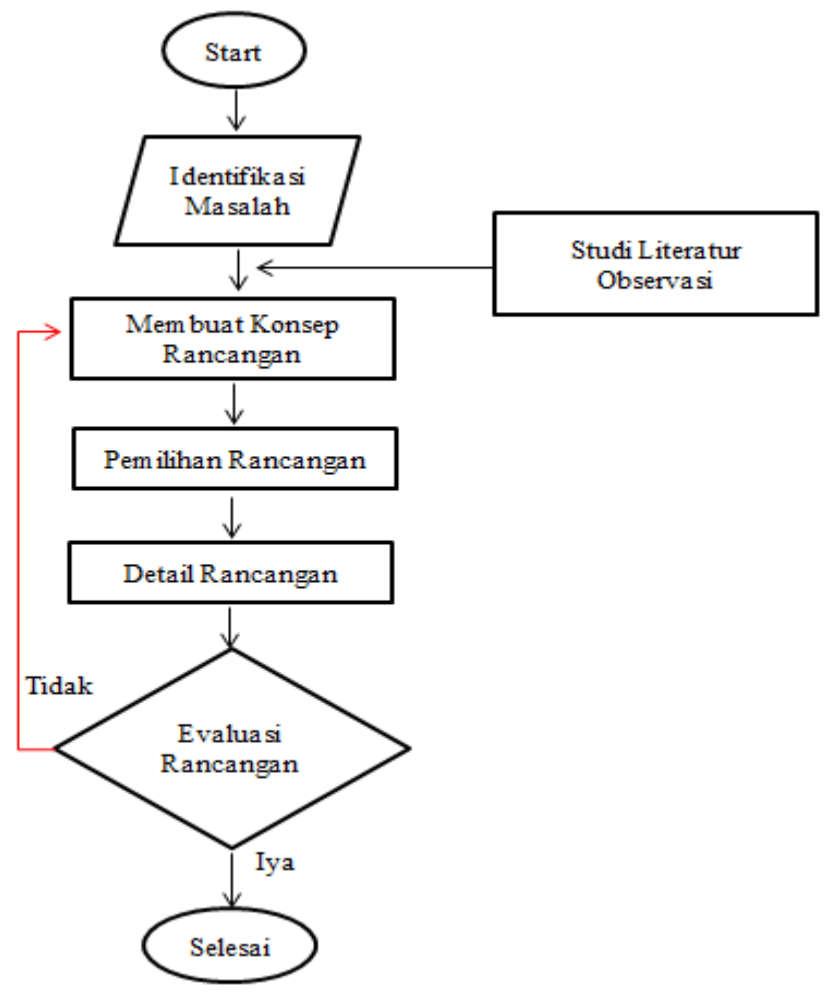

Gambar 1. Diagram Alir

\subsection{Pemilihan Rancangan}

Pada pemilihan rancangan ini terdapat beberapa komponen yang digunakan untuk membuat tungku dengan temperature maksimal $1200^{\circ} \mathrm{C}$.

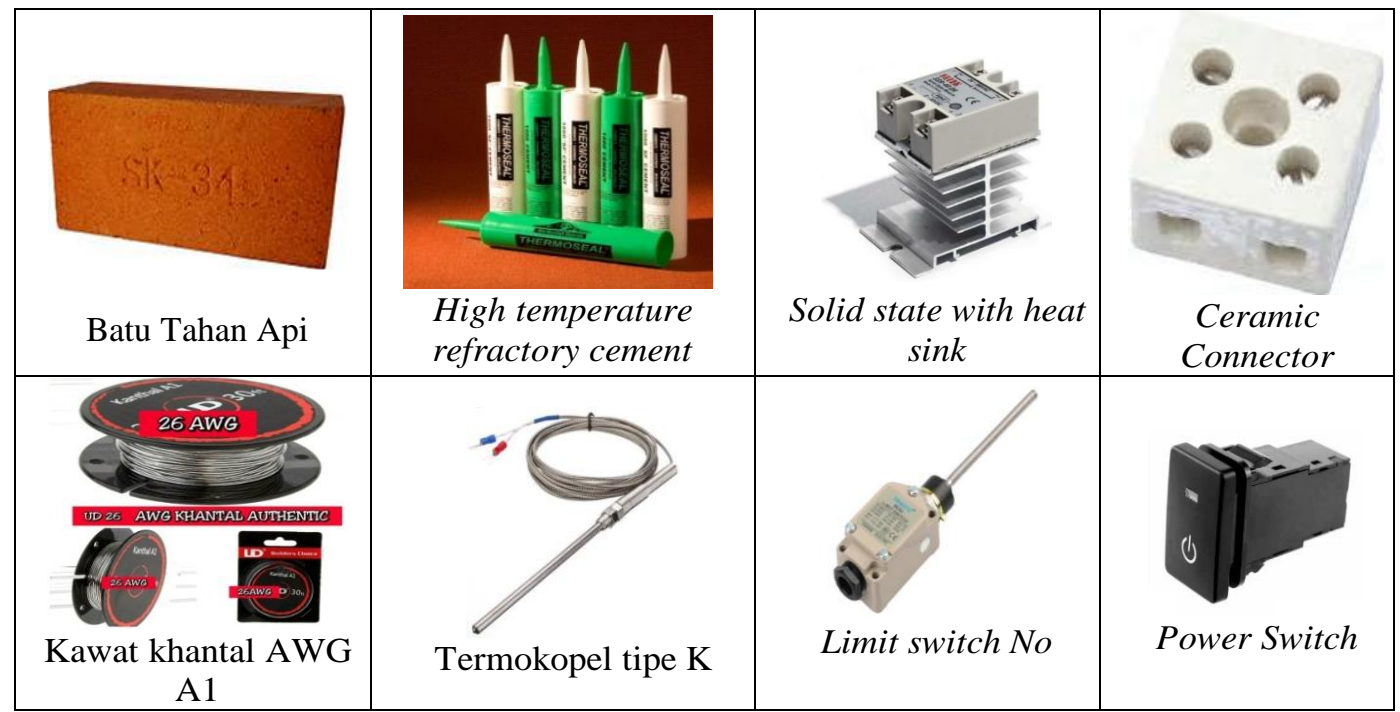




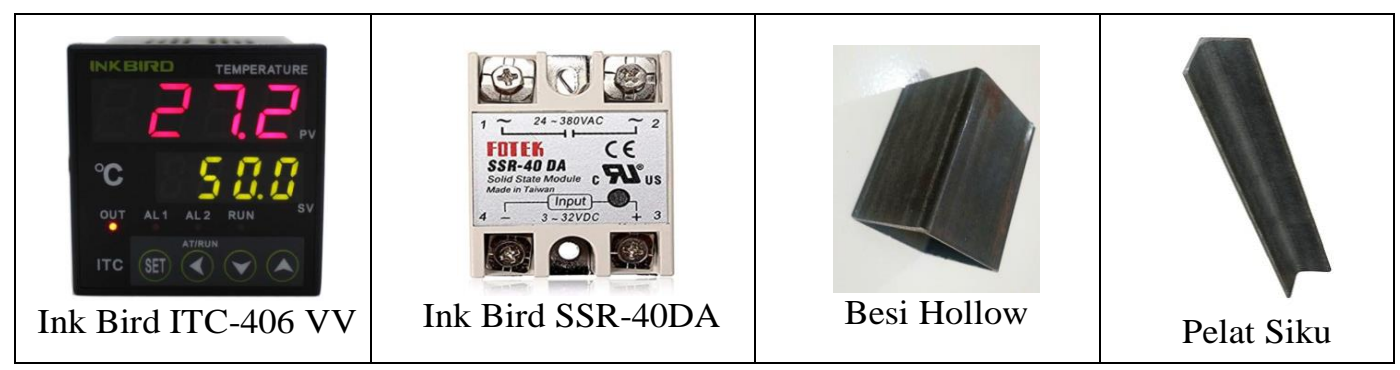

Gambar 2. Komponen tungku induksi

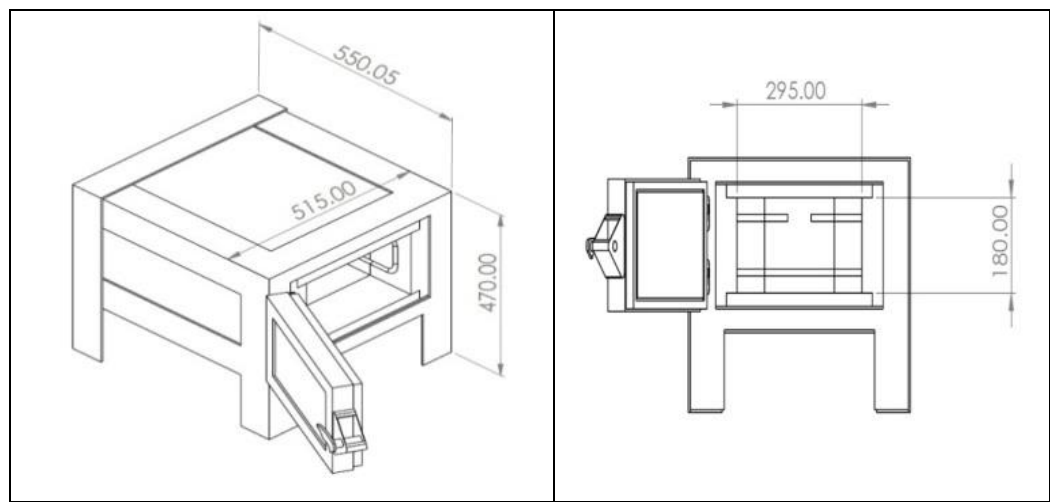

Gambar 3. Desain tungku dan identifikasi ukuran tungku

Konsep Rancangan untuk rangka pada tunggu dibuat dengan material dari pelat siku yang disambungkan dengan menggunakan 2 jenis metode, yang pertama menggunakan permanent joining process yaitu dengan pesawat las SMAW dan elektroda 260, yang kedua dengan menggunakan Threaded Fasteners yaitu baut dan mur.

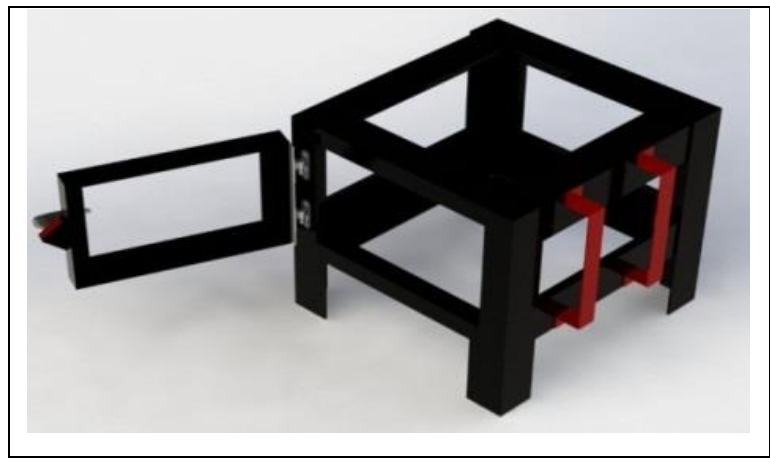

Gambar 4. Rangka tungku pemanas 


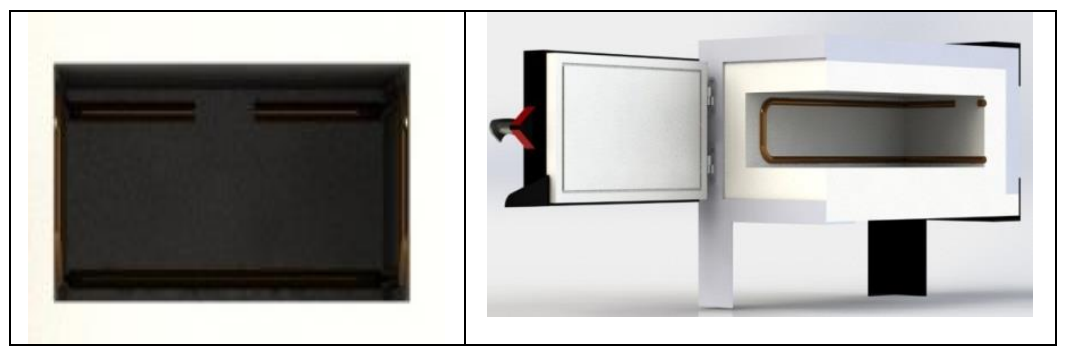

Gambar 5. Batang elemen pemanas

Keramik jenis ini lebih dikenal sebagai material yang tahan api serta tetap stabil pada temperatur yang tinggi. Refraktori tersebut tidak meleleh, tidak terdeformasi, mempunyai perubahan volume yang sangat kecil (baik perubahan volume terhadap penyusutan ataupun pemuaian), dan pembuatan rangka dengan menggunakan las listrik dan bahan materialnya dari baja dengan tebal $5 \mathrm{~mm}$.

\subsection{Pintu Tungku}

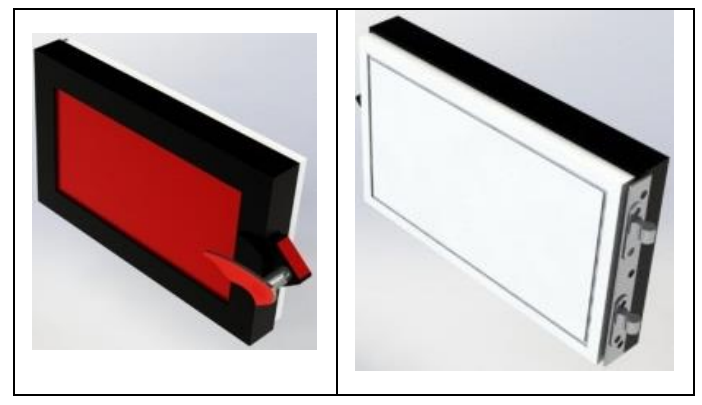

Gambar 6. Pintu tungku pemanas

Untuk bahan pada pintu menggunakan plat yang sama seperti pada rangka atau badan tungku dengan ukuran $345 \mathrm{~mm}$ x $230 \mathrm{~mm}$, dan untuk bahan pengisinya menggunakan keramik fiber blanket karena bahan ini lebih ringan, dan digolongkan pada refraktori yang berbasis serat aluminosilikat, putih, tidak berbau dan tahan suhu mencapai $120{ }^{\circ} \mathrm{C}$.

\subsection{Detail rancangan untuk Elemen Pemanas}

Komponen elemen pemanas pada tungku.

a. Elemen-elemen kanthal dapat digunakan sampai $1400^{\circ} \mathrm{C}$.

b. Tahanan jenis bahan ini $(1,35-1,45)$ X $10-6 \Omega \mathrm{m}$.

c. Bahan bahan Elemen Pemanas :

- Kawat yang digunakan

: Kawat kanthal

- Tahanan jenis kawat

: $0.195 \Omega$

- Berat

$: 50.5 \mathrm{~g} / \mathrm{m}$

- Diameter kawat

: $3 \mathrm{~mm}$

- Panjang kawat

$: 30 \mathrm{~m}$

- Dimeter batang pemanas

: $25 \mathrm{~mm}$

- Panjang Batang pemanas

: $279 \mathrm{~cm}$ 


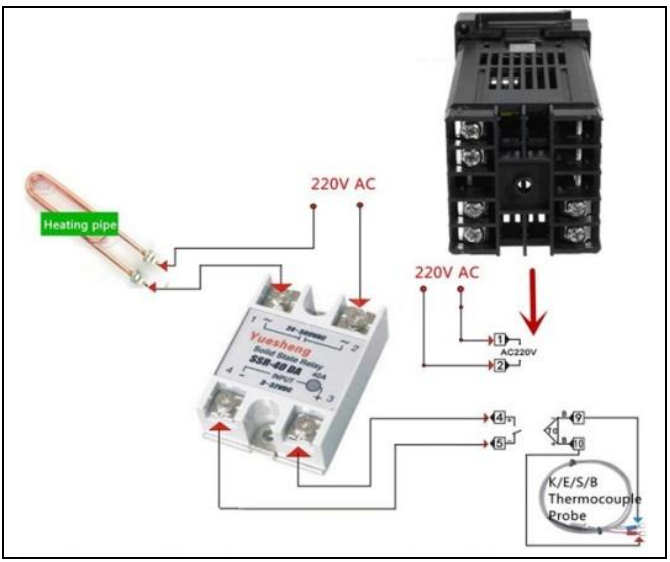

Gambar 7. Wiring Connection

\section{HASIL PERANCANGAN DAN PEMBAHASAN}

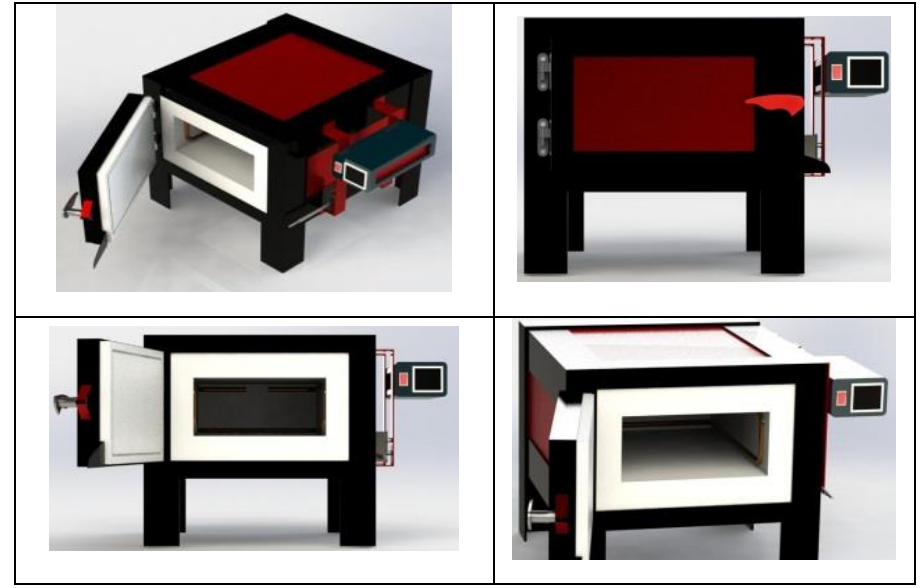

Gambar 8. Alat Tungku Pemanas

Perancangan yang dihasilkan dari tungku listrik yakni memanfaatkan energi listrik sebagai sumber panas yang diharapkan dapat mencapai temperatur $1200^{\circ} \mathrm{C}$ dalam waktu \pm 60 menit, sehingga dapat memanaskan material baja, aluminium maupun kuningan yang dapat dikontrol temperaturnya dengan menggunakan Ink Bird ITC-406 VV.

\subsection{Detail Rancangan Menghitung Berat Tungku}

A. Refraktori dan Badan Tungku

- Berat fire brick SK34:

$$
\begin{aligned}
\text { Volume } & =\mathrm{p} \times \ell \times \mathrm{t}=230 \times 114 \times 65=1.704 .300 \mathrm{~mm}^{3}=1.704,3 \mathrm{~cm}^{3} \\
\text { Jumlah Bata } & =40 \mathrm{pcs} \\
\text { Total volume } & =1704,3 \times 40=68.172 \mathrm{~cm}^{3} \\
\text { Berat } & =\mathrm{P} \times \mathrm{V}=0,8 \times 68.172=54,5376 \mathrm{~kg} \\
\text { - Batang Pemanas: } & \\
\text { Volume } & =(\pi / 4) \mathrm{d}^{2} \mathrm{t}=(\pi / 4) 25^{2} \times 115,5=56.667 \mathrm{~mm}^{3}=56,6 \mathrm{~cm}^{3} \\
\text { Jumlah Batang } & =2 \mathrm{pcs}
\end{aligned}
$$


Total volume $=56,6 \times 2=113,3 \mathrm{~cm}^{3}$

Berat batang $=\rho \times \mathrm{V}=0,23 \times 113,3=26,066 \mathrm{gr}=0,26 \mathrm{~kg}$

- Berat Plat Samping dan Atas:

$$
\begin{array}{ll}
\text { Volume } & =\mathrm{p} \times \ell \times \mathrm{t}=180 \times 295 \times 4=212.000 \mathrm{~mm}^{3}=212,4 \mathrm{~cm}^{3} \\
\text { Jumlah plat } & =4 \mathrm{pcs} \\
\text { V total } & =212,4 \times 4=849,6 \mathrm{~cm}^{3} \\
\text { Berat plat } & =\rho \times \mathrm{V}=7,64 \times 849,6=6.491 \mathrm{gr}=6.5 \mathrm{~kg}
\end{array}
$$

B. Pintu Tungku

Berat Pintu:

Volume $=\rho \times \ell \times \mathrm{t}=345 \times 230 \times 18=1.428 .300 \mathrm{~mm}^{3} 142.8 \mathrm{~cm}^{3}$

Berat $\quad=7,64 \times 142.8$

$$
\begin{aligned}
& =10.912 \mathrm{gr} \\
& =10.9 \mathrm{~kg}
\end{aligned}
$$

C. Total Berat Bahan Refraktori dan Badan Tungku

$$
10,9+6,5+0,26+54,53= \pm 75 \mathrm{~kg}
$$

\subsection{Menghitung Daya Listrik}

$\mathrm{R}=$ Panjang kawat $\mathrm{x}$ Tahanan jenis kawat

$$
=30 \mathrm{~m} \times 0.195 \Omega
$$$$
=5.85 \Omega
$$

$$
\begin{aligned}
P & =\frac{V 2}{R} \\
& =\frac{220^{2}}{5.85} \\
& =\frac{48.000}{5.85} \\
& =8205,1 \mathrm{watt} \\
& =8,2051 \mathrm{~kW}
\end{aligned}
$$

\subsection{Menghitung Kuat Arus Listrik}

$$
\begin{aligned}
\mathrm{I} & =\frac{P}{V} \\
& =\frac{8,2051}{220} \\
& =37,2 \mathrm{~A} \quad \text { [Menggunakan MCB 50 Ampere masih Aman] }
\end{aligned}
$$

\subsection{Konsumsi Pemakaian Listrik}

Konsumsi listrik dihitung dari temperatur dalam hingga $1200^{\circ} \mathrm{C}$.

Diketahui : Daya yang digunakan untuk mencapai $1200^{\circ} \mathrm{C}$ adalah : 8205,1 watt. Waktu yang di tempuh untuk mencapai $1200{ }^{\circ} \mathrm{C}$ adalah : \pm 36 menit. 


$$
\begin{aligned}
\mathrm{kWh} & =\frac{P}{1000} \times \frac{h}{60} \\
& =\frac{8205,1}{1000} \times \frac{36}{60} \\
& =8.2051 \times 0.6 \\
& =4.9 \mathrm{kWh}
\end{aligned}
$$

\section{EVALUASI RANCANGAN}

Analisis Kelayakan Ekonomi dan Keuangan Produk

Pada tahap ini terlebih dahulu dilakukan perhitungan biaya yang dikeluarkan untuk memproduksi satu unit Tungku Pemanas dengan pengeluaran total yakni \pm Rp. 5.000.000 diharapkan dapat dijual dengan harga yang lebih tinggi.

\section{KESIMPULAN}

Dari perancangan yang telah dilakukan, maka penulis dapat membuat kesimpulan sebagai berikut: material batu tahan api type SK34 dengan jumlah 40 Pcs memiliki temperatur maksimalnya $1400^{\circ} \mathrm{C}$, filament berbahan dasar $\mathrm{FeCrAl}$ sebagai penghantar panas menggunakan kanthal A1 yang digunakan sampai temperature $1200^{\circ} \mathrm{C}$ dengan panjang $279 \mathrm{~cm}$, konsumsi pemakaian listrik pada perancangan ini yakni $4.9 \mathrm{kWh} / 36$ menit. Desain yang dibuat menggunakan autocad dan solidwork dengan menghasilkan gambar 2D dan 3D berupa komponen - komponen tungku pemanas, tungku pemanas memiliki tinggi $47 \mathrm{~cm}$ panjang $51 \mathrm{~cm}$ dan lebar $55 \mathrm{~cm}$.

\section{SARAN}

Saran kedepannya ialah melakukan perubahan pada dimensi tungku sehingga mempunyai ruang kosong yang lebih besar, sehingga dapat menampung banyak material logam yang akan di heat treatment. 


\section{DAFTAR PUSTAKA}

[1] Suryana, Cahya. 2012. Trainer Dispenser Hot And Cool Unit Proyek Akhir. D3 Thesis. Negeri Yogyakarta

[2] Abrianto Akuan, 2009, "Tungku Peleburan Logam”

[3] Surdia, Tata, 1986, Teknik Pengecoran logam, Edisi kedua, PT Pradaya Paramita Bandung

[4] Yulianto, A., Darmawan, A. S., \& Wahyono, E. (2012). redesain dapur krusibel dan penggunaannya untuk mengetahui pengaruh pemakaian pasir resin pada cetakan centrifugal casting. jurusan teknik mesin universitas muhammadiyah Surakarta

[5] Alviandra. (2017). pengaruh penambahan unsur paduan magnesium pada Al-Si menggunakan dapur krusibel terhadap sifat kekerasan dan struktur mikro . jurusan teknik mesin universitas merdeka malang.

[6] Andhika, Dwi. (2009). Meneliti Hubungan Antara Kadar Tanah Liat Pada Cetakan Pengecoran Aluminium Dengan Kehaluhan Permukaan Hasil Cetak Dan Kekuatan Tarik. jurusan teknik mesin universitas malang.

[7] Istana, Budi, Lukman, Japri, (2012) Rancang bangun dan pengujian tungku peleburan aluminium berbahan bakar minyak bekas, jurusan teknik mesin universitas muhammadiyah riau.

[8] Arianto Leman .S. dan Tiwan, 2014 “ Pengembangan Tungku Peleburan Aluminium untuk Mengengembangkan kompetensi Pengecoran di SMK Prodi Keahlian Teknik Mesin.

[9] Muhammad Rais Rahmat, "Perancangan Dan Pembuatan Tungku Heat Treatment"Jurnal Imiah Teknik Mesin, Vol. 3, No.2 Agustus 2015 Universitas Islam 45 Bekasi,

[10] Hadyan gilang kurnia, 2013 "Sistem Instrumentasi Termokopel Jurusan Teknik Elektro Fakultas Teknik Univeresitas Diponegoro 2013.

[11] Agus Rizal, Yudi Samantha, Asep Rachmat, 2016 "PEMBUATAN TUNGKU PEMANAS (MUFLLE FURNACE) KAPASITAS $1200^{\circ} \mathrm{C}$ " Teknik Mesin, Fakultas Teknik, Universitas Majalengka.

[12] Ariffudin, S. D., \& Wulandari, D. (2014). Perancangan Sistem Pemanas Pada Rancang Bangun Mesin Pengaduk Bahan Baku Sabun Mandi Cair Satriya Dwi Ariffudin. Teknik Mesin, Universitas Negeri Surabaya, 1, 52-57. 